\title{
Expanding the Role of Digital Photographs in Evaluation Practice: Documenting, Sense-Making, and Imagining
}

\author{
Leanne M. Kallemeyn \\ School of Education, Loyola University Chicago
}

\begin{abstract}
Program stakeholders and evaluators routinely generate and share digital photographs. Three frameworks for using photographs in evaluation practice are discussed: documenting social change, facilitating sense-making, and inspiring and imagining social change. These are rooted in scholarship from arts-informed inquiry and visual sociology and anthropology. Using this framework, a review of existing literature demonstrates an extensive use of photographs for documentation and a growing use of photographs for sense-making and inspiring and imagining social change in evaluation practice. The paper concludes with a case example of how an evaluation team used digital photographs in an evaluation of a teacher professional development program.
\end{abstract}

Keywords: appreciative inquiry, learning-oriented evaluation, photo elicitation, photographs, photovoice

Résumé : Les personnes impliquées dans un programme et les évaluateurs du programme génèrent et partagent régulièrement des photographies numériques. L'auteur présente trois cadres pour l'utilisation de photographies dans la pratique de lévaluation: documenter les changements sociaux, donner du sens, inspirer et imaginer les changements sociaux. Cette analyse est tirée de recherches s'appuyant sur des démarches artistiques et provenant des domaines de la sociologie et de l'anthropologie visuelles. S’appuyant sur ce cadre, la revue de la littérature indique une utilisation intensive des photographies à des fins de documentation et une utilisation croissante des photographies pour donner du sens et inspirer et imaginer le changement social dans la pratique de lévaluation. À la fin de cet article, vous trouverez un exemple concret de la façon dont une équipe d'évaluation a utilisé des photographies numériques dans le cadre d'une évaluation d'un programme de perfectionnement professionnel des enseignants.

Mots clés : enquête appréciative, évaluation axée sur l'apprentissage, photo-interview, photographies, photovoix

Corresponding author: Leanne M. Kallemeyn, School of Education, Loyola University Chicago, 820 North Michigan Avenue, Chicago, IL 60611; lkallemeyn@luc.edu 
In 1995, Hurworth and Sweeney described the future possibilities for photography in evaluation:

some evaluators may feel daunted if they are not expert photographers.... Indeed with recent advances there is likely to be ever-increasing potential for visual approaches and data in evaluation. Options now include automatic cameras, cameras which record date and time, and increasingly lightweight video equipment. And, in the very near future the technology to scan images into computer programs and then to sort material in multiple ways will become more commonplace and will make it more plausible and exciting to include visual images in the evaluation process. (p. 163)

Digital technology has surpassed the "very near future" that Hurworth and Sweeney forecasted. People routinely use smartphones to take photographs that they share through email, instant messages, and social networking websites. These cultural practices are expanding people's understandings of what an image is and what it does when people use it to engage with one another.

Even though these cultural practices involving digital images are relatively new, the use of photographs has long traditions in visual sociology and anthropology (e.g., Chaplin, 1994; Harper, 2003; Margolis \& Pauwels, 2011; Mead, 1995; Pink, 2007; Prosser, 1998, 2005; Tinkler, 2013) and arts-based inquiry (e.g., Simons \& McCormack, 2007). Arts-based inquiry, in particular, is not new to the field of evaluation. Searle and Shulha (2016) provide a comprehensive overview of existing arts-based evaluation, particularly word-based approaches including stories, narratives, and dialogue. In this paper, I further contribute to arts-informed evaluation by exploring digital photographs, a visual approach.

I provide three frameworks for using photographs: documenting social change, facilitating sense-making, and inspiring and imagining social change. These frameworks are rooted in scholarship from arts-informed inquiry and visual sociology and anthropology. They provide a means to situate the existing literature on using digital photographs in evaluation practice. This review demonstrates an extensive use of photographs for documentation in evaluation and a growing use of photographs for sense-making. In contrast, evaluators have minimal examples of using photographs for inspiring and imagining social change. The paper concludes with a case example of how an evaluation team used digital photographs, in relation to the frameworks, in an evaluation of a teacher professional development program. The scholarship and case example challenge evaluators to shift from using photographs for documenting and sense-making to inspiring and imagining.

\section{FRAMEWORKS FOR INTEGRATING PHOTOGRAPHS IN EVALUATION PRACTICE}

Photographers frame pictures; in a similar manner, evaluators frame their practice. This section includes descriptions of three frameworks, or ways of thinking about the use of photographs in evaluation practice. The role and function of 
evaluation in society-mainly accountability (Christie \& Alkin, 2013), learning (Rogers \& Williams, 2006), and social change (Greene, 2006) - relate to the frameworks of documenting social change, facilitating sense-making, and inspiring and imagining social change, respectively. These frameworks shape what a photograph is and what it does in the context of an evaluation.

\section{Documenting social change}

A central purpose of evaluation is accountability (Christie \& Alkin, 2013), or being what they call "answerable" (p. 14). Evaluators provide an account of the program goals, processes, and/or outcomes to funders, policy-makers, the public, and possibly program participants. Such evaluations prioritize program effectiveness. In practice, these evaluations involve "oversight and compliance [to] estimate the extent to which a program meets specified expectations such as the directives of statutes, regulations, and other mandates, including requirements to reach specified levels of performance" (Mark, Henry, \& Julnes, 2000, p. 57). To achieve the aim of an evaluation for accountability purposes, evaluators are independent, external, and value-neutral.

Historically and currently, evaluators have been using photographs to provide an account, or as empirical evidence (Ardoin et al., 2014; Hurworth, 2004; Hurworth \& Sweeney, 1995; Patton, 2002; Rockwell, Albrecht, Nugent, \& Kunz, 2012). For example, an evaluator may take a picture at an event to document attendees. Evaluators have viewed photographs as factual "device[s] for documentation" (Sullivan, 2005, p. 63) or "records of reality" (Walker, 1993, p. 79), and they can represent mundane information about everyday life. Hurworth and Sweeney (1995) provide four examples of using photographs as a "source of data" (p. 153) in evaluation. Photographs from similar settings were compared and contrasted for evidence of achieving program goals. They were used as unobtrusive measures and then quantitatively coded on a variety of variables. Patton (2002) also provides examples of using photographs to represent the physical environment of an outdoor education program (p. 281) and to triangulate with other data sources (p. 308).

More recently, Rockwell and colleagues (2012) demonstrate the use of photographs in an evaluation of two non-formal educational programs, using Targeting Outcomes of Programs (TOP) as a structure. TOP documents program development and performance through seven stages: resources; activities; participation; reactions; knowledge, attitude, skill, and aspiration (KASA); practices; and social, economic, and environmental (SEE) conditions. The evaluators categorize the photographs based on these stages, which, they argue, helps address the potential subjectivities of photographs. Then the evaluators complement the photographs with other data sources in a mixed-methods design to provide documentation of a multi-year program.

As the previous examples illustrate, when evaluators use photographs as evidence, they position the stakeholders as passive sources of information, rather than co-participants in the evaluation. Harper (2003), a visual sociologist, 
cautions that the use of photographs as empirical evidence does not imply objective truth, as photographs also represent the interpretations of the photographer. The empirical evidence is both "constructed and real" (p. 183), which the next example illustrates.

Ardoin and colleagues (2014) used digital photographs with journalling to document triggers for situational interests in an environmental education program. Situational interests are catalysts for changes in attitudes, knowledge, skills, and behaviours. They provided participants with prompts for taking photographs and journalling about the photographs. Given the challenges of measuring situational interests as they occur in the moment, they viewed the use of photographs as a potentially authentic representation of students' experiences in this environmental education program. Although they allowed the students to be co-participants in the evaluation as photographers, the evaluators still interpreted the photographs as empirical evidence, rather than considering the participants' interpretations of their photographs. The evaluators categorized the majority of the photographs that students took as not related to the program. This outcome resulted in a challenge to differentiate what students viewed as their situational interests. This example illustrates the tensions in using photographs when evaluators want to use it for documentation but participants view taking photographs as engaging in sense-making.

\section{Facilitating sense-making}

An advantage of using photographs, or other arts-based research and evaluation approaches, is their ability to stimulate and facilitate sense-making (Harper, 2003; Pink, 2007; Prosser, 1998, 2005; Tinkler, 2013; Weber, 2008). Arts-informed inquiry is a complementary evaluation approach to qualitative methods (Searle \& Shulha, 2016). This section includes examples of how photographs have been used to facilitate sense-making and learning in evaluation practice.

In order for learning to occur in evaluation, the evaluation should be relevant to practitioners (Dahler-Larsen, 2009). To enhance relevance to practitioners, ownership or deep involvement is necessary from practitioners in the evaluation process. Because this approach requires trusting relationships, the appropriate social arena is typically a local group or community for this involvement. Similarly, Weiss (1998, p. 25) explains a role of evaluation as "organizational learning," which emphasizes focusing evaluation activities on program goals, providing feedback on practice and facilitating reflective practice, and understanding theories of change. Rogers and Williams (2006) identify various approaches to evaluation practice that are intended to support learning. These approaches include action research, appreciative inquiry, empowerment evaluation, evaluative inquiry, systemic evaluation, success case method, evidence-based practice, performance monitoring, and program theory. These approaches and assumptions frame how evaluators may integrate photographs into evaluation practice.

Given the widespread use of technologies that facilitate sharing digital images, people are continually engaging in this sense-making process. Photographs 
function more like spoken language in social interactions than as documentation of the past (van Dijck, 2008; Villi, 2007). Van Dijck argues that the growth in digital photographs has influenced the role of photographs in communicating identity formation. Villi describes "photo messaging," or digital images sent between smartphones, as a "new form of visual interpersonal communication" (p. 50). As a result, photographs are no longer primarily empirical evidence of what happened at significant moments; rather, they communicate immediately the present through representing ordinary, everyday moments. Through this communication, they also construct individuals' identities and tell stories.

When photographs are being used for sense-making, the task of the evaluator is to "understand how those who make images ... and those who interpret images ... construct their meanings as they present them in visual form" (Sullivan, 2005 , p. 63). For example, if an attendee took a picture of an event and shared it with someone who was unable to attend, then the evaluator might learn about the meaning of the event from the attendee's perspective in relation to his or her colleague. What is it that the photographer notices in the world? In what context is the viewer interpreting the photograph? As Walker $(1993$, p. 83) has noted, "[w]hat is important is not the image itself so much as the relationship between the image and the ways we make sense of it and the ways in which we value it."

Harper (2003) describes four approaches of using photographs in visual sociology. Three approaches, in particular, illustrate how photographs might facilitate sense-making. First, the phenomenological mode assumes that the "photographer chooses points of view that illuminate different aspects of the unfolding social reality" (p. 191). In other words, the photographs express the perspectives of the photographer. Rather than photography as a technical matter, it is more like an artistic expression.

Second, photographs can be selected and sequenced into visual narratives. Although video is the most common form of visual narrative, still photographs can also be sequenced to tell a story, which is particularly beneficial for studying social patterns. Although Rockwell et al. (2012) do not use terminology from visual sociology or arts-based inquiry, they emphasize the value of photography to "tell the story" (p. 179) of program implementation and impact. Using the TOP structure, they developed a narrative of the multi-year programs using photographs and other data sources. The photographs became critical evidence for making sense of the program theory and supporting program development. In particular, Rockwell et al. (2012) noted the benefits of capturing triumphs, illustrating practices and visions for change, and documenting unexpected outcomes.

Finally, Harper (2003) explains that photo elicitation involves presenting a set of photos to participants to generate their responses. These responses represent cultural meaning-making. Photo elicitation does not utilize photographs as a data source; rather, an evaluator or researcher uses photographs to prompt discussion in an interview or focus group. Photos facilitate dialogue and may generate rich evidence about difficult topics to recall or discuss (Tinkler, 2013). Given the limitations of interpreting a photograph, an interview provides opportunities to 
understand different perspectives of photographs, and to articulate new understandings.

Rockwell et al. (2012) provide an example of how they used photographs taken during a program evaluation as prompts in interviews with program participants. They conclude that photographs were particularly beneficial for helping participants reflect on their learning processes. Bessell, Deese, and Medina (2007) provide an overview of photolanguage, a form of photo elicitation, in evaluation. Photolanguage utilizes black-and-white photographs to "facilitate personal expression and interaction in small groups" (p. 558) and has roots in counseling and clinical therapy. Evaluators used universal images rather than images representing the evaluand to stimulate memory, emotions, imagination, and ideas. Similar to the role of interview questions, the photographs served as a way of prompting data generation in a focus group. Their research demonstrated that the use of this method resulted in richer, more extensive responses than in traditional focus-group methods.

Finally, photographs may facilitate sense-making during the reporting process. The phrase "a picture is worth a thousand words" (see Bessell et al., 2007) illustrates how rapidly people interpret photographs. As a result, using photographs in reporting is particularly effective. Fang (1985) and Rockwell et al. (2012) used photographs in reports to enhance written description.

\section{Imagining and inspiring social change}

In addition to accountability and learning, another central aim is social change among evaluators. Such an aim is most evident in evaluation approaches that embrace social justice, equality, empowerment, and transformation, such as deliberative democratic evaluation and, more recently, culturally and contextually responsive evaluation (Greene, 2006). These evaluators reject a clear distinction between facts and values and the possibility of value neutrality. Instead, they embrace particular value commitments intentionally and explicitly. They especially promote participatory approaches, since the involvement of a variety of stakeholders in the evaluation may be a means to address power imbalances. The role of the evaluator is then that of a facilitator and an advocate.

Simons and McCormack (2007) assert that arts-based approaches, such as photographs, provide opportunities for "holistic knowing" (p. 308) that integrate knowledge, emotions, and imagination. Images can evoke emotional responses that are memorable. They can help viewers empathize with the perspectives of others. For these reasons, they have the potential to stimulate action and social change (Weber, 2008). The photographs do not merely represent social change (Mitchell \& Allnutt, 2008); they spur it. A central element of facilitating social change is imagination. Mitchell and Allnutt (2008) articulate the "imaginative potential" (p. 260) of using photographs in inquiry processes. The use of photographs involves understanding the tensions between "what was" or "what is" and "what could be."

Photovoice (Lopez, 2010; Purington, Davis-Manigaulte, \& Powers, 2011) is an example of a participatory, transformative approach that utilizes photographs 
in evaluation. It is a "process by which people can identify, represent, and enhance their community through a specific photographic technique. It entrusts cameras to the hands of people to enable them to act as recorders, and potential catalysts for change, in their own communities" (Wang \& Burris, 1997, p. 369). Evaluators have used photovoice for needs assessments. In this participatory approach, photographs might be documentation of what participants see and experience, or they might be staged. Either way, the photographs represent the photographer's perspectives. A central aim is "to create pictorial narratives that convey what respondents want to communicate in the manner they wish to communicate" (Chalfen, 2011, p. 188). Chalfen provides an extensive overview of considerations in the process of designing a participatory or collaborative study that uses visuals. Photovoice and other arts-based approaches to evaluation can be used to "propel innovation" (Searle \& Shulha, 2016, p. 35).

\section{CASE EXAMPLE: BALANCED LITERACY PROFESSIONAL DEVELOPMENT PROGRAM FOR URBAN SCHOOLS}

This case example illustrates the use of photographs in an evaluation based on the three frameworks-documenting, sense-making, and inspiring and imaging. This case is intended to be exemplary, in the sense that it is an example rather than being exceptional (Thomas \& Myers, 2015). I am a practising evaluator, and this evaluation project challenged my assumptions about what a photograph is and what it does in the context of an evaluation.

\section{Program and evaluation context}

From 2010 to 2016, a university professor of reading and five school-based coaches collaborated with 10 urban elementary schools to establish systemic change in literacy instruction. The intent of these changes was to sustain balanced literacy instruction that integrated formative assessment and instructional standards (Policastro \& McTague, 2014; Policastro, McTague, \& Mazeski, 2015). The program began serving teachers and administrators in two urban schools with long histories of reform and external oversight. After six years, the project had served teachers and leaders in 10 schools, including seven public and three private schools. The main evaluation questions were the following: (1) What is the program theory based on program implementation? (2) What are the major successes and challenges of implementation? (3) What is the program impact for schools from diverse contexts? (4) What facilitates and inhibits these program impacts in diverse contexts? For schools involved in the project for five years, tenets of balanced literacy were part of teachers' daily instructional schedules. These tenets included read-alouds, guided reading, and literacy centres. A collaborative school culture via systems of teams facilitated these practices.

The evaluation team used responsive evaluation (Stake, 2004). This approach privileges local stakeholders, such as managers and practitioners, or university faculty, coaches, administrators, and teachers, as the audience of the evaluation. 
It also assumes that the evaluator adapts the evaluation in response to the context. Although this evaluation was not explicitly participatory, it was what Cousins and Whitmore (1998) refer to as practical participatory evaluation, in that the evaluation team involved stakeholders in the evaluation in an effort to promote utilization. Dahler-Larsen (2009) identifies Stake's responsive evaluation and Cousins and Whitmore's practical participatory evaluation as approaches to evaluation that facilitate learning.

Based on funder requirements, the evaluation team used a logic model rooted in the program theory to evaluate program implementation and impact (Rogers, Petrosino, Huebner, \& Hacsi, 2000). The evaluation team viewed the logic model as dynamic. Throughout the six-year project, the team also integrated appreciative inquiry (Preskill \& Catsambas, 2006) and visual ethnography (Harper, 2003). Due to the small annual evaluation budget ( $\$ 12,000-\$ 15,000$ annually), the team integrated data sources that were relatively inexpensive to use and that program stakeholders could monitor in conjunction with their program administration, including surveys with two stakeholder groups, secondary analysis of student assessment data, annual visits to schools to interview key stakeholders and observe activities, and document analysis of program materials and resources. The evaluation used mixed methods, with a primary emphasis on qualitative methods. The program received funding from a state-level agency, which had received a federal grant. The project also received technical and statewide meta-evaluation from a team at a state university.

During the six years of the program, teachers went on strike and then threatened to strike again due to difficult contract negotiations in this large urban district. Schools had uncertain budgets and significant cuts that affected staffing. In response to new state laws, the district rolled out new performance evaluation systems for principals and teachers that integrated student test scores and systematic observations. The district also introduced publicly available balanced score cards for schools, coupled with a controversial ranking system. In year 3 of the project, the district also closed 49 schools, including an original school of the project that served as a demonstration site to other schools. Due to this experience and others, administrators and teachers also switched schools frequently.

In the initial meeting with the client and program implementers, the evaluation team worked on articulating a logic model, per funder requirements, and brainstormed data sources and methods to represent the elements of the logic model. At the close of this meeting, in a side conversation, the university professor serving as program developer mentioned, "Oh by the way, I plan to take photographs of these schools before we start working in them and then also throughout the process." In the first year, the evaluation team then integrated these digital photographs, taken primarily by the program developer, as an evidence source into the evaluation. All photographers were amateurs with minimal knowledge of principles of photography such as lighting and composition.

The benefits of using photographs became evident quickly. First, the images spoke to the beauty and justice resulting from the project (House, 1980). Second, the use of photographs fostered appreciation for the project and dialogue regarding project aims, in the midst of barriers (e.g., pending teacher strikes, school 
closures) that distracted from project work. Third, the photographs facilitated model diffusion. Finally, they facilitated rapid, formative feedback loops regarding inappropriate and absent practices, which provided opportunities for program staff members to address shortcomings.

Although the role of, and emphasis on, the photographs adapted throughout the six years of the project, these benefits remained constant. In addition, program stakeholders had assumptions about other traditional methods, such as teacher surveys and various student reading assessments, that misaligned with the aims of the project and how knowledge would be used in the project. For example, teacher surveys were used to provide input regarding school improvement and inform a school performance ranking system, the results of which were publicly posted on the Web. The photographs were not used for such dual purposes.

Dahler-Larsen (2009) provides three arguments for the relationship between evaluation for accountability and learning, which can also apply to the three frames-accountability, learning, and social change-of evaluation discussed in this paper. Because a democratic society demands an accountability function, all purposes are necessary. As a result, learning-oriented and action-oriented approaches can adapt to cooperate with accountability-oriented approaches to evaluation. In the section that follows, accountability, learning, and social action distinctly frame the use of photographs in evaluation practice. Despite these apparent distinctions, like Dahler-Larsen I assume that evaluation for accountability, learning, and social action coexisted.

\section{Documenting social change in the case example}

Although I do not consider documenting change as the central role of photographs in this evaluation, this purpose coexisted with the other frames. I particularly used this frame when reporting to funders. Figure 1 provides documentation of a parent library that was set up in the main hallway in the demonstration school, and a guided reading library in a former storage room. The program developer took all photographs. When the evaluation team shared these photographs in annual reports to the funder, the photographs provided documentation of the change and accomplishments. To formalize this documentation, the evaluation team also used a checklist of photographs to take during annual site visits to each school (Hurworth, 2004; Hurworth \& Sweeney, 1995). This checklist represented elements in the program model that the team wanted to document whether and how they were being implemented in the schools. Although these photographs were beneficial in reporting to funders, in contrast to the photographs that stakeholders generated, they had less meaning and value for the local stakeholders when the evaluation team created them. As the program continued, the program developer and the evaluator shifted the emphasis from documenting with photographs to sense-making with photographs.

\section{Facilitating sense-making in the case example}

In the evaluation of the teacher professional development program, the evaluation team experimented with using photographs to foster sense-making about the program. Weekly emails and coach reflection logs included narratives that 


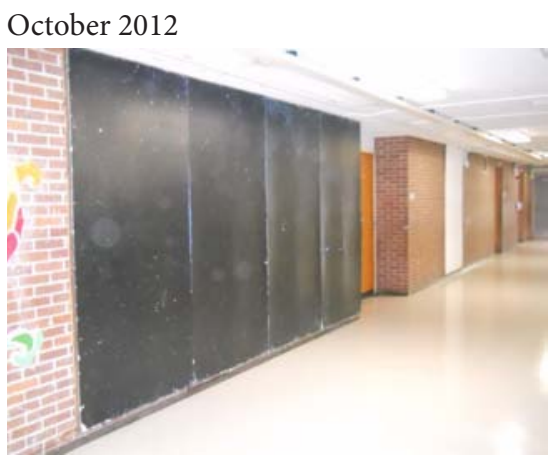

\section{October 2012}
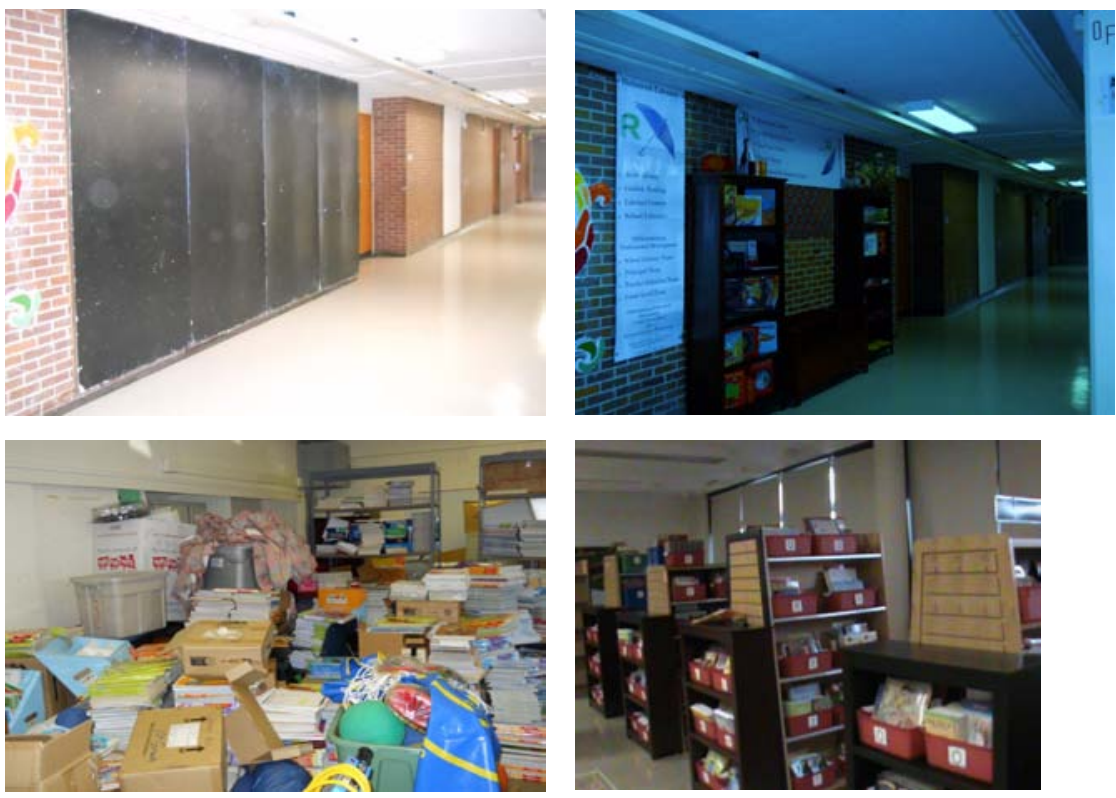

March 2012

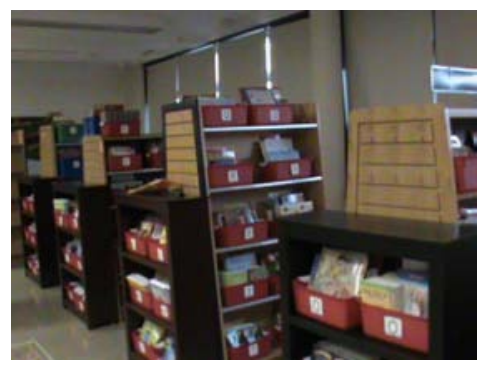

January 2013

Figure 1. Documenting Changes to Physical Spaces, including a Parent Library (top) and a Guided Reading Library (bottom).

gave meaning to the photographs, particularly from the perspectives of those taking them. As a viewer of the photographs, I often had additional questions about them. I also wanted to further encourage the use of photographs to make sense of program implementation and impact. In informal conversations with key stakeholders, I found that we routinely constructed narratives about the program from photographs.

For example, one sense-making strategy, which is common in arts-based evaluation (Simons \& McCormack, 2007), is the use of metaphors. Figure 2 represents three different perspectives of balanced literacy. Most notably, each photograph depicted an umbrella, which was a metaphor that the program developer used to communicate the concept of balanced literacy. Comparing and contrasting these photographs demonstrated that stakeholders had both common and different understandings of core concepts in the program model. The program developer took the photograph on the left during the first year of the initiative. It contains a banner displayed in the demonstration school, which represented the program model; thus, it represented her perspective of balanced literacy. The program developer also took the photograph on the top right-hand corner, which represents a bulletin board that school staff members at the demonstration school created a few months later. The last photograph represents a 


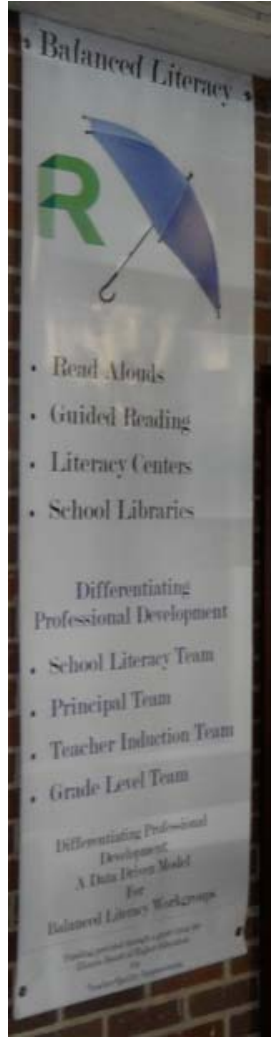

November 2010

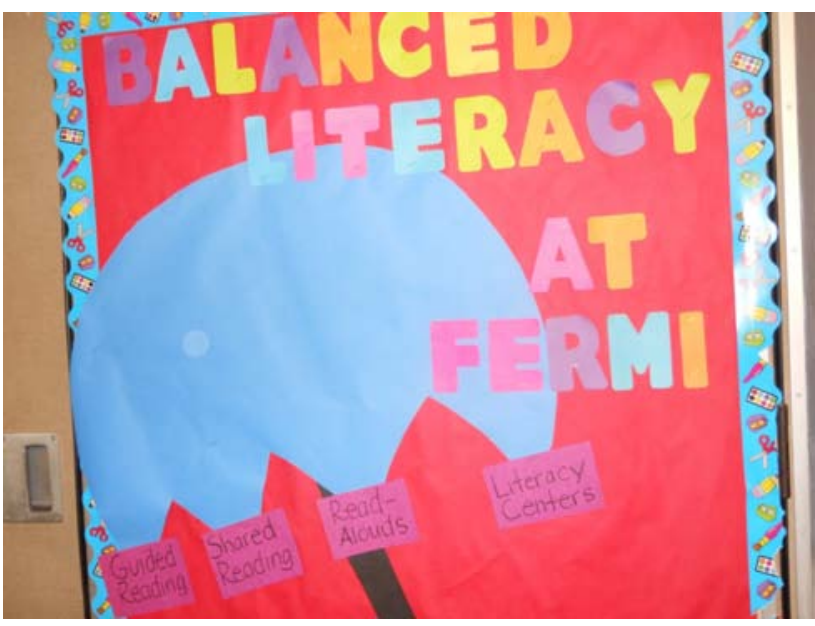

February 2011

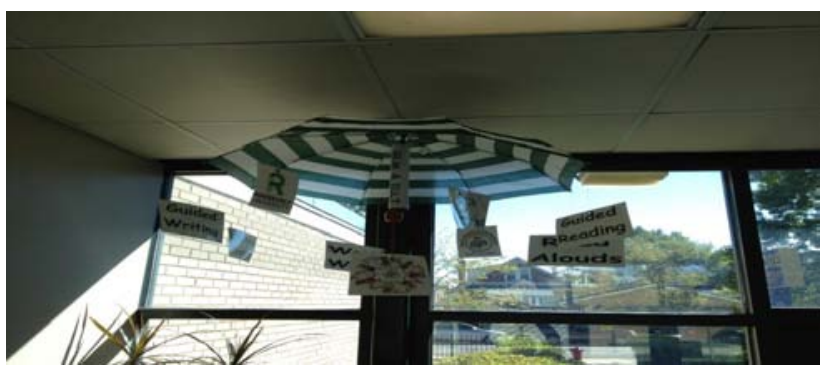

September 2012

Figure 2. Sense-making through the metaphor of an umbrella and multiple interpretations of the program model.

hallway mobile in a dissemination school, which joined the initiative during its third year. A staff member took the photograph and emailed it to the program developer. Although viewers cannot read all of the elements of the program model in the photograph, they can see two components that were consistent with the other models_ "read alouds" and "guided reading"-and also see a new concept-“guided writing."

Another sense-making strategy is developing narratives (Harper, 2003; Sullivan, 2005). Rephotography (Rieger, 2011) uses photographs to represent social change by ordering them temporally and comparing multiple time points. This sequencing can be used for storytelling. The evaluation team used this strategy in the third year and then in subsequent evaluation reports. The top half of Figure 3 includes a collage of proud moments at a dissemination school three months after the school joined the initiative, either sent to the program developer or taken by the program developer took during a school visit. The 


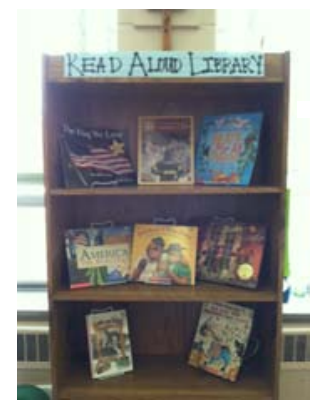

October 2012
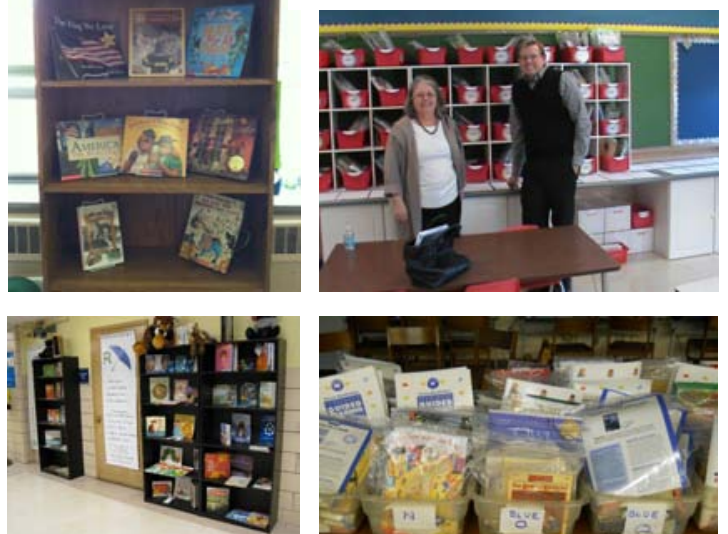

September 2011

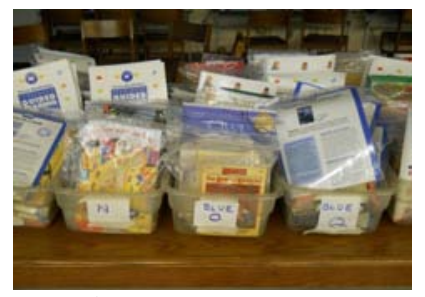

September 2011
October 2012
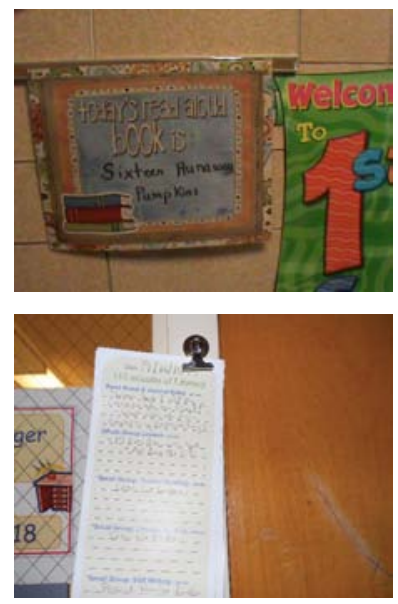

January 2011

Figure 3. Illustration of Rephotography through collage of proud moments in a dissemination school (top) and an original school (bottom).

bottom half of Figure 3 presents photographs of these same proud moments in the original school. The same activities were spread across the first year. Based on photographic evidence, at least one dissemination school was quickly implementing the program model. The differences in the length of time might be for a variety of reasons, but this evidence demonstrated a finding that was explored further and confirmed in other data sources of the evaluation. More important, these accomplishments were rapidly communicated between program stakeholders. This example demonstrates how rephotography might be used to sequence photographs and tell visual narratives. The photographic collage provided a vignette (Stake, 1995) of program implementation from each school.

Although the evaluation team experimented with photo elicitation (Harper, 2003) during site-visit interviews with teachers and administrators, I found this approach less beneficial in this evaluation. The photographs were usually ordinary objects and activities that the interviewees were accustomed to viewing on a daily basis. Also, when participants had not taken any photographs to discuss, they were not interested in discussing photographs taken by other individuals. For this reason, I attempted to have teachers and administrators take, and then discuss, their photographs, but the everyday realities in the schools interfered with this as a routine practice.

The evaluation team, in collaboration with the program developer who took the majority of the photographs, selected 30 to 40 photographs to illustrate the 
various components of the program logic model on an annual basis. Using PowerPoint or a web-based resource, the evaluation team arranged them sequentially in a three-to-four-minute slideshow that they shared as part of an oral evaluation report to local stakeholders. After the slideshow, the evaluation team had stakeholders reflect on what they saw, using questions from appreciative inquiry (Preskill \& Catsambas, 2006). Through these slideshows, the evaluation team provided a story about the status of program implementation. The team also incorporated a link to this slideshow in the report to the funders. After the team's use of photographs in early reports, other grantees across the state were also encouraged to use photographs.

In an effort to formalize this sense-making process on a routine basis, the evaluation team experimented with conducting interviews with program photographers on a quarterly basis using an interview protocol that I developed for program stakeholders (see Appendix). The aim of this protocol was to assist the stakeholders and evaluation team in selecting, sequencing, and interpreting the photographs. This protocol was based on appreciative inquiry (Preskill \& Catsambas, 2006) and the concept of rephotography (Rieger, 2011). Stakeholders found this process meaningful and productive. Unfortunately, shortly after the evaluation team began implementing it in Year 4, the photographic evidence became less central in the overall program, so these interviews were less relevant.

\section{Imagining and inspiring social change in the case example}

In this project, photographs were taken of "what was" in some schools in an effort to communicate "what could be" in other schools (Mitchell \& Allnutt, 2008). The program developer sent out weekly emails to all program participants, documenting accomplishments from the previous week and upcoming activities. She began to attach photographs she had taken to illustrate the accomplishments, and eventually PowerPoint presentations with photographs and captions. The evaluation team conducted a document analysis of these emails and attachments across time. For example, in Figure 1, the photograph on the bottom left shows the chaotic materials in a storage room. The second photograph represents how the school's literacy team transformed this storage room into a professional development room for teachers, which contained a guided reading library with organized and usable instructional materials.

As the project moved into new schools and began scaling up, the program developer used the photographs to orient new schools to the project. In the process of understanding and constructing the meaning of the photographs, the stakeholders were also identifying universals within the particulars (Simons \& McCormack, 2007), or the extraordinary in the ordinary. The particulars are the personal, private meanings of what is happening in a photograph, and why a person took it. A universal audience should then be able to understand this unique experience of particular people, in a particular place, at a particular time. Figure 3 demonstrates how the new schools more quickly implemented core elements of 
the program. Stakeholders attributed this rapid implementation as partly related to the photographs that provided clear guidance and visuals.

In the third year, the evaluation team encouraged school-level stakeholders to take photographs with smartphones and iPads and then share them with the evaluation team. Relatively few people did so, but many school-level staff members took photographs, which they sent to the program developer via email. She in turn included them in her weekly emails. School-level stakeholders wanted the program developer to see what they were accomplishing in relation to the initiative in their schools. When stakeholders shared photographs, it was also a way to celebrate accomplishments.

The evaluation team found that stakeholders took photographs of proud moments. The evaluation team found that "creative expression helps participants translate their tacit knowledge into an evaluation context and acknowledges their contributions" (Simons \& McCormack, 2007, p. 30). At one point, the program developer refused to take photographs of poor instructional practices, as she did not want to emphasize and share such practices. To illustrate this tendency of "proud photography," the top half of Figure 3 includes two pictures a staff member from a dissemination school sent to the program developer via email within the first three months of the school joining the initiative. The photographs illustrated accomplishments of school staff members, including teachers' read-aloud displays and parent libraries at the entrance of the school. These photographs communicated what had been accomplished-access to reading materials and the use of read alouds; thus, these strengths could be built upon. They also communicated what had not been accomplished-the development of guided reading libraries and changes to classroom instruction-which the evaluation team inquired about further with other data-collection tools in the evaluation. In this way, the absence of evidence facilitated the process of valuing.

When program stakeholders took photographs of their "proud moments," this process also provided a means to make value judgments. For example, when initiating a new program emphasis on formative assessment, the program director had school staff members send her proud moments from their practice in which they were using formative assessment. Her interpretation of the photographs was that the school staff had a misunderstanding of what formative assessment was. She did not value what was being represented as aligned with the aims of the program. This new understanding then shaped future professional development activities, revisiting topics addressed with new insights into teachers' existing understandings of formative assessment.

In sum, this case example demonstrates how using photographs for documentation, sense-making, and inspiring and imagining coexisted. More important, it demonstrates the value of photographs in the process of refining and scaling up an initiative. I also experimented with approaches for integrating the photographs into the evaluation that focused on sense-making and inspiring social change, including metaphors (Simons \& McCormack, 2007), visual narratives, photo elicitation (Harper, 2003), rephotography (Rieger, 2011), and 
imagining (Mitchell \& Allnutt, 2008). I encouraged stakeholders to routinely take and share photographs of their practices. This process facilitated formative assessment about program implementation and sense-making about the program theory of change. This process also assisted stakeholders in translating tacit knowledge about the program to others (Simons \& McCormack, 2007). I found that stakeholders took photographs of "proud moments," which was critical for inspiring and imagining social change as the project implementation increased from two to 10 schools.

\section{Cautions}

As with all methods and data sources, evaluators should use photographs with caution. Despite the successes that the evaluation team experienced when choosing to integrate photographs, I also took missteps in the process of adapting the use of photographs over the life of the program. First, photographs are not appropriate data sources in all evaluations, nor should evaluators use photographs in all evaluations. Hurworth (2004) provides a review of "photographic evaluation" (p. 164) based on how she used photographs as key data sources in several evaluations. She concluded that photographs were particularly beneficial in evaluation practice in the following circumstances: when a wide range of activity is to be documented; when stakeholders are unable to participate in other forms of data collection, such as surveys or interviews (e.g., children, participants with low literacy levels, participants with disabilities); when they serve as an unobtrusive measure; when program objectives are abstract and therefore difficult to articulate or measure; when programs are highly visual in themselves, such as in the arts; when programs lead to change over long or short time periods; when the physical/ locational context of a program is important; and in interactive, empowerment, participatory, and/or collaborative evaluations. In the case example, photographs were unobtrusive measures that documented the physical environments and changes over time, which in this program were central to program implementation and short-term outcomes.

Second, in contrast to the changes in the physical environments in the schools at the beginning of the project, the program outcomes, which included changes in teachers' instructional practice and student learning, were much more difficult to represent with photographs. The evaluation team also had minimal funding to support a broader use of photographs or to shift to videos. As a result, an initially valued evidence source had minimal value in the evaluation. The evaluation team struggled to find credible and persuasive evidence sources to represent these outcomes for stakeholders after the positive experiences with photographs. The inability to represent long-term program outcomes adequately with photographs might have discouraged the practitioners from attending to program outcomes, as they favoured photographic evidence over other data sources in the evaluation. Ethical issues of privacy further complicated this issue, as the team avoided photographs with faces (Fang \& Ellwein, 1990). Although people take photographs of each other and share them in a public manner on a 
daily basis, ethics in evaluation and legal guidelines in schools respect the privacy of individuals and the sharing of their identity through photographs in reports and publications.

Third, although photographs can be a means to voice and address power imbalances (Tinkler, 2013), when stakeholders do not take photographs, it minimizes their voice in the evaluation. There is danger that the photographer's presence takes authority and may overpower the perspectives of other stakeholders. When this occurs, the photographs become more about the photographer than about the subject matter within the photographs. Although the program developer took many photographs, and some coaches and school leaders took some too, the evaluation team had difficulty representing the project from multiple perspectives with photographs. The evaluation team became increasingly concerned that the photographs may be telling only one version of the program story, which is counterproductive in democratic approaches (Greene, 2006) and responsive evaluation (Abma, 2006).

The photographs were intended to be a means to foster respect and to build trust in order to share experiences, both of which are essential in responsive evaluation (Abma, 2006) and evaluation for social change (Greene, 2006). Although photographs are by no means the only tool or approach to effect such transformative relationships, this case example demonstrated that they may be a useful tool for doing so.

\section{CONCLUSION}

In many evaluation contexts, it is easy to generate and share digital photographs. This fairly recent trend could expand the relevance of arts-based inquiry in evaluation to a variety of contexts, including the teacher professional development initiative that served as a case example in this paper. As evaluators integrate photographs into their practice, the profession also needs to move away from a framework that views a photograph only as an unobtrusive measure that documents the implementation and impact of a program. This framework fails to take advantage of recent cultural shifts in the use of photographs for constructing and communicating identities and accomplishments. It minimizes the potential for learning and sense-making via photographs and ignores their potential for imagining and inspiring social change. Evaluators should draw upon the literature in arts-informed research and visual sociology and anthropology to reframe how they use photographs in their practice.

\section{ACKNOWLEDGEMENTS}

This paper would not have been possible without the work of Dr. Margaret Policastro, Diane Morrison, literacy coaches for the project, administrators in project schools, Cliff McReynolds, and Jana Grabarek. 


\section{REFERENCES}

Abma, T.A. (2006). The practice and politics of responsive evaluation. American Journal of Evaluation, 27(1), 31-43. https://doi.org/10.1177/1098214005283189

Ardoin, N.M., DiGiano, M., Bundy, J., Chang, S., Holthuis, N., \& O’Connor, K. (2014). Using digital photography and journaling in evaluation of field-based environmental education programs. Studies in Educational Evaluation, 41, 68-76. https://doi. org/10.1016/j.stueduc.2013.09.009

Bessell, A.G., Deese, W.B., \& Medina, A.L. (2007). Photolanguage: How a picture can inspire a thousand words. American Journal of Evaluation, 28(4), 558-569. https://doi. org/10.1177/1098214007306372

Chalfen, R. (2011). Differentiating practices of participatory visual media production. In E. Margolis \& L. Pauwels (Eds.), The SAGE handbook of visual research methods (pp. 186-200). Los Angeles, CA: SAGE Publications. https://doi. org/10.4135/9781446268278.n10

Chaplin, E. (1994). Sociology and visual representation. London, England: Routledge. https://doi.org/10.4324/9780203416723

Christie, C., \& Alkin, M. (2013). An evaluation theory tree. In M. Alkin (Ed.), Evaluation roots: $A$ wider perspective of theorists' views and influences (2nd ed., pp. 11-57). Thousand Oaks, CA: SAGE Publications.

Cousins, J.B., \& Whitmore, E. (1998). Framing participatory evaluation. In E. Whitmore (Ed.), Understanding and practicing participatory evaluation (pp. 5-23). San Francisco, CA: Jossey-Bass.

Dahler-Larsen, P. (2009). Learning-oriented educational evaluation in contemporary society. In K.E. Ryan \& J.B. Cousins (Eds.), The SAGE international handbook of educational evaluation (pp. 307-322). Los Angeles, CA: SAGE Publications. https://doi. org/10.4135/9781452226606.n17

Fang, W.L. (1985). Using photographs in an evaluation report. Evaluation News, 6(2), 24-27.

Fang, W.L., \& Ellwein, M.C. (1990). Photography and ethics in evaluation. Evaluation Review, 14(1), 100-107. https://doi.org/10.1177/0193841X9001400107

Greene, J.C. (2006). Evaluation, democracy, and social change. In I.F. Shaw, J.C. Greene, \& M.M. Mark (Eds.), The SAGE handbook of evaluation (pp. 118-140). Thousand Oaks, CA: SAGE Publications. https://doi.org/10.4135/9781848608078.n5

Harper, D. (2003). Reimaging visual methods: Galileo to Neuromancer. In N.K. Denzin \& Y.S. Lincoln (Eds.), Collecting and interpreting qualitative materials (2nd ed., pp. 107-154). Thousand Oaks, CA: SAGE Publications.

House, E. (1980). Evaluating with validity. Thousand Oaks, CA: SAGE Publications.

Hurworth, R. (2004). The use of the visual medium for program evaluation. In. C.J. Pole (Ed.), Seeing is believing? Approaches to visual research (pp.163-181). Bingley, England: Emerald Group. https://doi.org/10.1016/S1042-3192(04)07010-7

Hurworth, R., \& Sweeney, M. (1995). The use of the visual image in a variety of Australian evaluations. Evaluation Practice, 16(2), 153-164. https://doi.org/10.1016/08861633(95)90024-1 
Lopez, K.K. (2010). Using PhotoVoice to engage stakeholders in empowerment evaluations. Retrieved from http://comm.eval.org/coffee_break_webinars/Go.aspx?c=ViewDocu ment\&DocumentKey=facfa903-7866-451f-85cc-568ff7e8674d.

Margolis, E. \& Pauwels, L. (Eds.). (2011). The SAGE handbook of visual research methods. Los Angeles, CA: SAGE Publications. https://doi.org/10.4135/9781446268278

Mark, M.M., Henry, G.T., \& Julnes, G. (2000). Evaluation: An integrated framework for understanding, guiding, and improving policies and programs. San Francisco, CA: Jossey-Bass.

Mead, M. (1995). Visual anthropology in a discipline of words. In P. Hockings (Ed.), Principles of visual anthropology (3rd ed., pp. 3-12). Berlin, Germany: Walter de Gruyter. https://doi.org/10.1515/9783110290691.3

Mitchell, C., \& Allnutt, S. (2008). Photographs and/as social documentary. In J.G. Knowles \& A.L. Cole (Eds.), Handbook of the arts in qualitative research: Perspectives, methodologies, examples, and issues (pp. 251-261). London, England: SAGE Publications. https://doi.org/10.4135/9781452226545.n21

Patton, M.Q. (2002). Qualitative research and evaluation methods (3rd ed.). Thousand Oaks, CA: SAGE Publications.

Pink, S. (2007). Doing visual ethnography. London, England: SAGE Publications. https:// doi.org/10.4135/9780857025029

Policastro, M.M., \& McTague, B. (2014). The new balanced literacy school: Implementing Common Core. North Mankato, MN: Maupin House.

Policastro, M.M., McTague, B., \& Mazeski, D. (2015). Formative Assessment in the New Balanced Literacy Classroom. North Mankato, MN: Maupin House.

Preskill, H., \& Catsambas, T.T. (2006). Reframing evaluation through appreciative inquiry. Thousand Oaks, CA: SAGE Publications.

Prosser, J. (1998). Image-based research: A sourcebook for qualitative researchers. London, England: Falmer Press.

Prosser, J. (2005). Image-based research: A sourcebook for qualitative researchers. London, England: Taylor \& Francis e-Library.

Purington, A., Davis-Manigaulte, J., \& Powers, J. (2011). Using photovoice for participatory community evaluation. Demonstration session at the annual meeting of the American Evaluation Association, Anaheim, CA.

Rieger, J. (2011). Rephotography for documenting social change. In E. Margolis \& L. Pauwels (Eds.), The SAGE handbook of visual research methods (pp. 132-149). Los Angeles, CA: SAGE Publications. https://doi.org/10.4135/9781446268278.n7

Rockwell, S.K., Albrecht, J.A., Nugent, G.C., \& Kunz, G.M. (2012). Using targeting outcomes of programs as a framework to target photographic events in nonformal educational programs. American Journal of Evaluation, 33(2), 179-194. https://doi. org/10.1177/1098214011421522

Rogers, P.J., Petrosino, A., Huebner, T.A., \& Hacsi, T.A. (2000). Program theory evaluation: Practice, promise, and problems. In P.J. Rogers, T.A. Hacsi, A. Petrosino, \& T.A. Heubner (Eds.), Program theory in evaluation: Challenges and opportunities (pp. 5-13). San Francisco, CA: Jossey-Bass. https://doi.org/10.1002/ev.1177 
Rogers, P.J., \& Williams, B. (2006). Evaluation for practice improvement and organizational learning. In I.F. Shaw, J.C. Greene, \& M.M. Mark (Eds.), The SAGE handbook of evaluation (pp. 76-97). London, England: SAGE Publications. https://doi. org/10.4135/9781848608078.n3

Searle, M.J., \& Shulha, L.M. (2016). Capturing the imagination: Arts-informed inquiry as a method in program evaluation. Canadian Journal of Program Evaluation, 31(1), 34-60. https://doi.org/10.3138/cjpe.258

Simons, H., \& McCormack, B. (2007). Integrating arts-based inquiry in evaluation methodology: Opportunities and challenges. Qualitative Inquiry, 13(2), 292-311. https:// doi.org/10.1177/1077800406295622

Stake, R. (1995). The art of case study research. Thousand Oaks, CA: SAGE Publications.

Stake, R. (2004). Standards-based responsive evaluation. Thousand Oaks, CA: SAGE Publications. https://doi.org/10.4135/9781412985932

Sullivan, G. (2005). Art practice as research: Inquiry in the visual arts. Thousand Oaks, CA: SAGE Publications.

Thomas, G., \& Myers, K. (2015). The anatomy of the case study. London, England: SAGE Publications. https://doi.org/10.4135/9781473920156

Tinkler, P. (2013). Using photographs in social and historical research. Los Angeles, CA: SAGE Publications.

van Dijck, J. (2008). Digital photography: Communication, identity, memory. Visual Communication, 7(1), 57-76. https://doi.org/10.1177/1470357207084865

Villi, M. (2007). Mobile visual communication: Photo messages and camera phone photography. Nordicom Review, 28(1), 49-62. https://doi.org/10.1515/nor-2017-0200

Walker, R. (1993). Finding a silent voice for the researcher: Using photographs in evaluation and research. In M. Schratz (Ed.), Qualitative voices in educational research (pp. 72-92). London, England: Falmer Press.

Wang, C., \& Burris, M.A. (1997). Photovoice: Concept, methodology, and use for participatory needs assessment. Health Education \& Behavior, 24(3), 369-387. https://doi. org/10.1177/109019819702400309

Weber, S. (2008). Using visual images in research. In J.G. Knowles \& A.L. Cole (Eds.), Handbook of the arts in qualitative research: Perspectives, methodologies, examples, and issues (pp. 41-54). London, England: SAGE Publications. https://doi. org/10.4135/9781452226545.n4

Weiss, C.H. (1998). Evaluation (2nd ed.). Upper Saddle River, NJ: Prentice Hall.

\section{AUTHOR INFORMATION}

Leanne M. Kallemeyn is an associate professor in Research Methodologies in the School of Education at Loyola University Chicago. 


\section{Appendix: Protocol for Digital Photography Storytelling and Reflective Practice [60-90 minutes]}

\section{PREPARATION FOR MEETING}

Have the interviewee select 20-30 photographs taken from to that represent his/her experiences with the program.

\section{DURING THE MEETING}

1. Did you share any photographs that you brought the last time we met? With whom did you share them and why?

2. Have you already shared any photographs that you brought today? With whom did you share them and why?

[For the remaining questions, have the interviewee choose a photograph or a series of photographs, to discuss in response to each of the questions.]

\section{Successes}

3. When did you feel most energized and most proud to be a part of this program? Tell me the story behind this photograph, or series of photographs.

4. Without being modest, what do you value most about this program and your work with this program?

\section{Program Theory/Logic Model}

5. What has been happening in the life of this program? Which photographs represent components of the program model?

6. Do any of the photographs represent an outcome of the program model or a change that has occurred?

\section{Change Over Time}

7. Do any of these photographs remind you of photographs that you have taken previously? Which ones and why?

8. What similarities and differences do you notice between the photographs you took this time compared to the photographs you took last time?

\section{Moving Forward}

9. If you would share a photograph or series of photographs with others, which ones would you choose and why? With whom would you share them? 
10. If you had three wishes of what you would like to be able to take a photograph of, what would they be? What aspects of the program model are not represented in the photographs that you want to see represented?

\section{Wrap-up}

11. Are there any photographs that you brought which have not come up in the conversation? Tell me about them. Why was this photograph important to you?

12. Briefly look through all the photographs taken, to be sure that in the course of the interview you have documented basic information about each photograph, including location, names/roles of key people in the photographs, and the photographer. 